Journal for ImmunoTherapy of Cancer

\title{
First-in-human DR5 PET reveals insufficient DR5 expression in patients with gastrointestinal cancer
}

\author{
Shujing Wang, ${ }^{1,2,3}$ Hua Zhu, ${ }^{1,2,3}$ Yingjie Li, ${ }^{3,4}$ Jin Ding, ${ }^{1,2,3}$ Feng Wang, ${ }^{1,2,3}$ \\ Lixin Ding, ${ }^{1,2,3}$ Xinyu Wang, ${ }^{3,4}$ Jun Zhao, ${ }^{3,4}$ Yan Zhang, ${ }^{1,2,3}$ Yunfeng Yao, ${ }^{3,4}$ \\ Tong Zhou, ${ }^{5}$ Nan Li, ${ }^{1,2,3}$ Aiwen Wu, ${ }^{3,4}$ Zhi Yang (D) 1,2,3
}

To cite: Wang S, Zhu H, Li Y, et al. First-in-human DR5 PET reveals insufficient DR5 expression in patients with gastrointestinal cancer. Journal for ImmunoTherapy of Cancer 2021;9:e002926. doi:10.1136/ jitc-2021-002926

- Additional online supplemental material is published online only. To view, please visit the journal online (http://dx.doi.org/10.1136/jitc2021-002926).

SW, $\mathrm{HZ}$ and $\mathrm{YL}$ contributed equally.

Accepted 25 June 2021

Check for updates

(C) Author(s) (or their employer(s)) 2021. Re-use permitted under CC BY-NC. No commercial re-use. See rights and permissions. Published by BMJ.

For numbered affiliations see end of article.

\section{Correspondence to \\ Professor Nan Li;} rainbow6283@sina.com

Professor Aiwen Wu; wuaw@sina.com

Professor Zhi Yang; pekyz@163.com

\section{ABSTRACT}

Background Death receptor 5 (DR5) is a promising therapeutic target for cancer therapy. However, many clinical trials of DR5 agonists failed to show significant therapeutic efficacy in patients with cancer. The study aimed to investigate the feasibility of using ${ }^{89} \mathrm{Zr}$-CTB006 positron emission tomography (PET) for noninvasive imaging of DR5 expression in preclinical models and patients with gastrointestinal (GI) cancers.

Methods Balb/c, Sp2/0 xenograft and patient-derived tumor xenograft were employed for micro-PET/CT imaging in vivo. In the clinical study, patients with Gl cancers planning to undergo surgical operation were enrolled and underwent ${ }^{18} \mathrm{~F}$-FDG and ${ }^{89} \mathrm{Zr}$-CTB006 PET/CT. The tumor tissues were obtained through surgical operation and DR5 expression levels were confirmed by RNAscope.

Results Preclinical studies showed that ${ }^{89} \mathrm{Zr}$-CTB006 PET could specifically detect DR5 expression levels in vivo. Twenty-one patients, including nine gastric cancers and 12 colorectal cancers, were enrolled. The biodistribution showed high uptake in the liver and spleen and low uptake in the brain, lung and muscle with an acceptable whole-body dosimetry of $0.349 \mathrm{mSv} / \mathrm{MBq}$. Strikingly, the adrenal glands maintained stable high uptake over the entire examination in all patients. The tumor lesions showed different levels of uptake of ${ }^{89} \mathrm{Zr}$-CTB006 with a mean maximum standardized uptake value $\left(\mathrm{SUV}_{\max }\right)$ of $6.63 \pm 3.29$ (range 1.8-13.8). Tumor tissue was obtained from 18 patients, and ${ }^{89} \mathrm{Zr}$-CTB006 uptake in patients with RNAscope scores of 3-4 was significantly higher than that in patients with scores of $0-2$. An SUV max $_{\text {of }} 9.3$ at 48 hours and 6.3 at 72 hours could be used to discriminate the DR5 expression status of tumors both with a sensitivity and specificity of $100 \%$ and $92.9 \%$, respectively.

Conclusions ${ }^{89} \mathrm{Zr}$-CTB006 PET/CT is capable of detecting DR5 expression in cancer patients and is a promising approach to screen patients with DR5 overexpression.

\section{INTRODUCTION}

Death receptor 5 (DR5), also known as tumor necrosis factor (TNF)-related apoptosisinducing ligand receptor 2 (TRAIL-R2), is a necessary ligand for inducing the apoptosis of tumor cells. ${ }^{1}$ Conventional anticancer therapies (chemotherapy and radiotherapy) induce apoptosis through the endogenous mitochondrial signaling pathway, while the TNF family ligands can induce apoptosis through the exogenous pathway when combined with their naturally stimulating TRAIL or agonist antibodies. ${ }^{2-4}$ DR5, as a receptor of TRAIL, is widely expressed on the surface of tumor cells, but rarely on normal cells. ${ }^{5-7}$ The rate of DR5 expression was previously reported to be $60.0 \%-100.0 \%$ in a range of malignant tumors while only low levels of DR5 were found in few normal cells. ${ }^{8}$ Based on its selective antitumor ability in a series of preclinical studies, ${ }^{9}$ DR5 has become a potential target for improving the efficacy and safety of tumor therapy. Several DR5 monoclonal agonist antibodies such as conatumab, tigatumumab (CS1008), and lexatumumab have been developed and have shown good safety and antitumor effects in some tumor patients in phase I and II clinical trials. ${ }^{10}$ However, no clinical trials have reached the expected end points, such as improving objective response rate, progressionfree survival, and overall survival. This finding suggests that clinical trials of DR5 agonistic antibodies have difficulty achieving success in unselected patients. ${ }^{11} 12$ Therefore, it is necessary to identify a method to screen patients who will benefit from DR5 agonistic antibody therapy for clinical trials.

In 2015, a phase I trial of CS-1008 in patients with metastatic colorectal cancer showed that the clinical benefit rate (stable disease and partial response) in patients with ${ }^{111}$ In-CS1008 uptake in tumors was $58.0 \%$ vs $28.0 \%$ in patients without uptake through ${ }^{111}$ In-CS-1008 single photon emission computed tomography (SPECT) imaging, suggesting that ${ }^{111}$ In-CS1008 SPECT imaging is predictive of the clinical benefit of DR5 agonistic antibody therapy. ${ }^{13}$ However, due to the low resolution and lack of quantitative capability of SPECT, ${ }^{111}$ In-CS1008 SPECT imaging is not practical for clinical application. Positron emission tomography computed tomography (PET/CT) with higher 


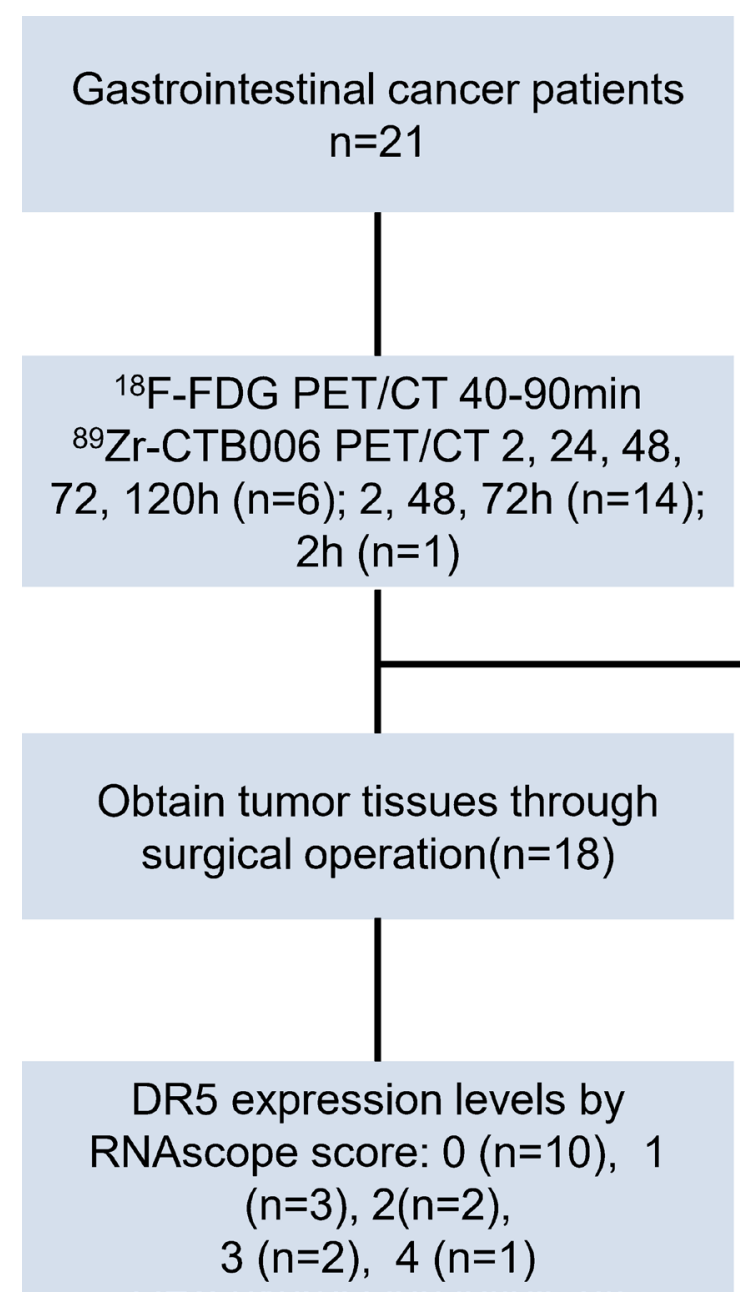

Figure 1 Trial profile: 21 patients (14 male, 7 female ) with a mean age of 58 years (range, 35-75) were enrolled, including 12 colorectal patients with cancers and 9 patients with gastric cancers. One patient withdrew for individual reasons after the first imaging of ${ }^{89} \mathrm{Zr}$-CTB006 PET/CT. The tumor tissues of 18 patients were obtained and 10 patients' RNAscope scores were 0 ; 3 patients' were 1; 2 patients' were 2; 2 patients' were 3 ; 1 patient' was 4.

spatial resolution, higher sensitivity than SPECT and quantitative capability is expected to be a better method for screening patients benefiting from DR5 agonistic antibody therapy.

CTB006 is a humanized chimeric recombinant antihuman DR5 monoclonal antibody that can specifically bind to DR5 and has been approved by the National Medical Products Administration for clinical trials (No. 2015L02216). We established a noninvasive approach using the new radionuclide ${ }^{89} \mathrm{Zr}$-labeled СТВ006 to perform PET/CT imaging in order to assess the DR5 expression in animals and patients. Both preclinical and clinical studies showed that ${ }^{89} \mathrm{Zr}$-CTB006 PET/CT could noninvasively detect DR5 expression in tumor lesions, which was pathologically confirmed by RNAscope. These results suggest that DR5 expression screening in oncology patients for DR5 targeting therapy should be taken into consideration.

\section{MATERIALS AND METHODS}

\section{Study design}

The study aimed to evaluate a PET tracer ${ }^{89} \mathrm{Zr}$-CTB006 for detecting DR5 expression status quantitatively and non-invasively from animals to patients, and validate the benefit from CTB006 therapy in patients with tumor ${ }^{89} \mathrm{Zr}$-CTB006 uptake. The clinical trial was an open-label, single site, prospective study (figure 1) and registered on Chinese Clinical Trail Registry (ChiCTR2100042022). The objective was to determine the safety, dosimetry, biodistribution and the tumor uptake of ${ }^{89} \mathrm{Zr}$-СTB006, and investigate the potential of the ${ }^{89} \mathrm{Zr}$-CTB006 PET/ CT to detect DR5 expression and screen DR5 overexpression patients with gastrointestinal cancers. All patients provided written informed consents.

\section{Materials and experimental animals}

The Colo205 cell line, N87 cell line were purchased from American type culture collection. ${ }^{89} \mathrm{Zr}$ was produced and purified by the Nuclear Medicine Department of Beijing Cancer Hospital. The CTB006 monoclonal antibody, Balb/c mice, mice-bearing Colo205 xenografts and Sp2/0 xenografts, mice-bearing CS225 and CS263 patient-derived tumor xenografts (PDX) were provided by Sinotau (Beijing, China). All procedures in studies involving animals were performed in accordance with 
the ethical standards of the institutional and/or national research committee.

\section{Radiolabeling and quality control of ${ }^{89} \mathrm{Zr}$-СTB006}

${ }^{89} \mathrm{Zr}$ was coupled with CTB006 via the bifunctional metal ion chelate deferoxamine in solution with $\mathrm{pH} 7.0$ for 1 hour. Then a PD-10 column was used to generated ${ }^{89} \mathrm{Zr}$-CTB006 with radiochemical purity (RP) of $>95.0 \%$. Quality control was conducted using radioactive thinlayer chromatography (Bioscan, IAR-2000, Washington, District of Columbia, USA) and high-performance liquid chromatography (Agilent, Lake Forest, California, USA) in a standard protocol.

\section{In vitro cell binding affinity}

A serial dilution of DR5 positive Colo205 cells $\left(1 \times 10^{7} / \mathrm{mL}\right.$, $5 \times 10^{6} / \mathrm{mL}, 2.5 \times 10^{6} / \mathrm{mL}, 1.25 \times 10^{6} / \mathrm{mL}, 0.625 \times 10^{6} / \mathrm{mL}$, $\left.0.31 \times 10^{6} / \mathrm{mL}\right)$ and DR5 negative N87 cells $\left(1 \times 10^{7} / \mathrm{mL}\right)$, BGC803 $\left(1 \times 10^{7} / \mathrm{mL}\right)$ were incubated for 1 hour with $4 \mu \mathrm{g} / \mathrm{mL}(7.4 \mathrm{~Bq})$ at room temperature. After incubation, cells were centrifuged and the activity in the cell pellet was measured in a gamma counter.

\section{Animal studies}

Biodistribution study of ${ }^{89} \mathrm{Zr}$-CTB006 in mice

Female Balb/c mice were injected with $5.18 \mathrm{MBq}$ ${ }^{89} \mathrm{Zr}$-CTB006 and sacrificed at $10 \mathrm{~min}, 1$ hour, 4 hours, 24 hours, 48 hours, 96 hours, 168 hours, 312 hours ( $n=5$ per time point) after injection. The main organs were harvested, weighed, and measured in a gamma counter. The percent injected dose per gram $(\% \mathrm{ID} / \mathrm{g})$ was calculated by comparison to a weighed, diluted standard.

\section{${ }^{89} \mathrm{Zr}$-СТВ006 PET imaging in mice tumor models}

Female mice-bearing Colo205 xenografts (DR5 positive model of human colorectal cancer) and $\mathrm{Sp} 2 / 0$ xenografts (DR5 negative model of human myeloma) were divided into experimental group $(n=4)$, blocking $\operatorname{group}(n=4)$, control group $(n=4)$ and free ${ }^{89} \mathrm{Zr}$ group $(\mathrm{n}=2)$. For PET/ CT imaging, $3.7 \mathrm{MBq}^{89} \mathrm{Zr}$-CTB006 was injected per mouse for the experiment group, blocking group, control group while $30 \mathrm{mg} / \mathrm{kg}$ CTB006 was coinjected for the blocking group, and ${ }^{89} \mathrm{Zr}$ was injected per mouse for the free ${ }^{89} \mathrm{Zr}$ group. Static PET/CT scans were performed for $10 \mathrm{~min}$ at 1 hour, 6 hours, 24 hours, 48 hours, 96 hours, 168 hours, 312 hours after injection with the SNPC-103 micro-PET/CT (Pingsheng, China). After reconstruction, the images were processed by image processing software PMOD (Zürich, Switzerland). Mice-bearing CS225 and CS263 xenografts, two PDX established from a lung cancer patient with high DR5 expression (with RNAscope score of 4) and a patient with colorectal cancer with medium DR5 expression (with RNAscope score of 3), respectively, were obtained. Static PET/CT scans were performed for $30 \mathrm{~min} 14$ days after administration of $7.4 \mathrm{MBq}{ }^{89} \mathrm{Zr}$-CTB006 per mouse $(\mathrm{n}=3)$. After scanning, the original data were reconstructed and processed by image processing software. The mice were sacrificed to obtain major organs, which were weighed by balance and measured by the gamma count to calculate the $\% \mathrm{ID} / \mathrm{g}$ value.

\section{Eligibility criteria of patients in the clinical trial}

For the prospective clinical trial, patients with pathological confirmed gastrointestinal cancers who would undergo surgical operation, with an Eastern Cooperative Oncology Group performance status $\leq 2$, were eligible. Other inclusion criteria were an age between $18-75$ years; a life expectancy of at least 3 months; and adequate liver and renal function. Patients who were pregnant, allergic to research drugs, unable to tolerate the whole examination, or suffering from claustrophobia were excluded.

\section{${ }^{89} \mathrm{Zr}$-CTB006 PET/CT and ${ }^{18} \mathrm{~F}$-FDG PET/CT in patients}

All patients underwent ${ }^{18} \mathrm{~F}$-flurodeoxyglucose $\left({ }^{18} \mathrm{~F}\right.$-FDG $)$ PET/CT and ${ }^{89} \mathrm{Zr}$-CTB006 PET/CT after 52.77 $\pm 11 \mathrm{MBq}$ ${ }^{89} \mathrm{Zr}$-CTB006 injection. The first 6 patients underwent ${ }^{89} \mathrm{Zr}$-CTB006 PET/CT at 2 hours, 24 hours, 48 hours, 72 hours, 120 hours after injection of ${ }^{89} \mathrm{Zr}$-CTB006 with Siemens Biograph mCT Flow 64 scanner (Erlangen, Germany). Others underwent ${ }^{89} \mathrm{Zr}$-CTB006 PET/CT at 2 hours, 48 hours, 72 hours after the ${ }^{89} \mathrm{Zr}$-CTB006 injection. PET images were acquired from head to upper thigh with scan speeds of $0.8 \mathrm{~mm} / \mathrm{s}, 0.5 \mathrm{~mm} / \mathrm{s}, 0.4 \mathrm{~mm} / \mathrm{s}$, $0.3 \mathrm{~mm} / \mathrm{s}$ and $0.2 \mathrm{~mm} / \mathrm{s}$ at 2 hour, 24 hours, 48 hours, 72 hours/96hours, 120 hours, respectively, and were reconstructed using the ordered-subset expectation maximization method. Images were interpreted by two experienced nuclear medicine physicians who were aware of the patient's history. The maximum standardized uptake value $\left(\mathrm{SUV}_{\max }\right)$ of the tumors was measured. The uptake ratio of the tumor to the adrenal glands $\left(\mathrm{SUV}_{\text {ratio }}\right)$ was calculated with the use of $\mathrm{SUV}_{\text {max }}$ of the tumor and $\mathrm{SUV}_{\text {mean }}$ of the adrenal glands.

\section{${ }^{89} \mathrm{Zr}$-СTB006 biodistribution and dosimetry evaluation in human}

$\mathrm{SUV}_{\text {mean }}$ in main organs based on the whole-body uptake of ${ }^{89} \mathrm{Zr}$-CTB006 was evaluated. Volume of interests were drawn on the main organs including the brain, lung, heart, liver, spleen, kidneys, muscle, and bone on the PET/CT images to measure their activity concentration with the IntelliSpace Portal workstations (Philips, Netherlands). Values of standard male/female organ masses were taken from the Organ Level Internal Dose Assessment(OLINDA/EXM) software (V.2.2, HERMES Medical Solutions, Canada) and the human organ dosimetry was estimated.

\section{DR5 expression in obtained tumor tissue using RNAscope}

An mRNA in situ hybridization (ISH) technique named RNAscope was used to investigate the DR5 expression in the tumor lesions. RNAscope 2.5 HD Brown Detection Kit (Advanced Cell Diagnostics, Hayward, California, USA) and RNAscope Probes for DR5 mRNA were applied, according to the manufacturer's instruction. ${ }^{14}$ Probes are hybridized for 2 hours and followed by a cascade of signal amplification for enhancing the signal. According 
to the signal number in the cells, the staining results were scoring into five levels (score 0-4, online supplemental table 1). Each sample was quality controlled with a probe specific to the house keeping PPIB mRNA for positive control and a probe specific to bacterial dapB gene for negative control.

\section{Safety evaluation}

All patients underwent the measurement of vital signs (blood pressure, heart rates, respiratory rate, and temperature), clinical laboratory testing (blood routine examination, routine urinalysis, hepatic and renal function examination) and electrocardiography before and 72 hours after ${ }^{89} \mathrm{Zr}$-CTB006 administration.

\section{Statistical analysis}

Descriptive statistics included median or mean and SD. Comparisons between groups were done using the onesamples t-test and relationship between two groups were done using pearson correlation analysis. The receiver operating characteristic (ROC) curves were computed for $\mathrm{SUV}_{\max }$ and $\mathrm{SUV}_{\text {ratio }}$ for evaluating the ability to detect DR5 expression status and the optimum cut-off value was obtained with Yoden index. Statistical analysis was performed with the IBM SPSS software (V.20.0; IBM).

\section{RESULTS}

\section{In vitro cell binding affinity}

CTB006 was efficiently radiolabeled with ${ }^{89} \mathrm{Zr}$ and passed the quality control for clinical application (online supplemental table 2). The average radiolabeling efficiency and RP are $96.9 \% \pm 0.5 \%(\mathrm{n}=21)$ and over $97.4 \%(\mathrm{n}=21)$, respectively. ${ }^{89} \mathrm{Zr}$-CTB006 showed the highest binding affinity for Colo205 cells while the binding affinities for N87 and BGC803 cells were lower. The dissociation constant $\left(\mathrm{K}_{\mathrm{d}}\right)$ of ${ }^{89} \mathrm{Zr}$-CTB006 was $65.24 \mathrm{nmol}$, as calculated by a one site saturation binding affinity test (online supplemental figure $1 G$ ).

\section{Animal study}

Female Balb/c mice were injected with $5.18 \mathrm{MBq}$ ${ }^{89} \mathrm{Zr}$-CTB006. The biodistribution results showed high uptake in the heart, liver, lung, spleen, kidney and blood. The uptake in the marrow increased slowly while the uptake in the other organs decreased with time.

Mice with Colo205 and Sp0/2 tumors were injected with $3.7 \mathrm{MBq}{ }^{89} \mathrm{Zr}$-CTB006 for imaging via the tail vein. The Colo205 tumor in the experimental group showed obvious uptake of ${ }^{89} \mathrm{Zr}$-CTB006 and had the highest uptake at 168 hours after administration (\% ID/g: 12.75 \pm 3.81 ) (online supplemental figure 1). The experimental group showed significantly higher uptake in tumors than the blocking group $(\% \mathrm{ID} / \mathrm{g}$ : $12.75 \pm 3.81$ vs $8.21 \pm 1.16, \mathrm{p}<0.05)$, the control group (\% ID/g: $12.75 \pm 3.81$ vs $4.34 \pm 0.55, \mathrm{p}<0.01)$ and the free ${ }^{89} \mathrm{Zr}$ group $(\% \mathrm{ID} / \mathrm{g}: 12.75 \pm 3.81$ vs $3.88 \pm 1.93$, $\mathrm{p}<0.01)$.

PDX model mice were injected with $7.4 \mathrm{MBq}{ }^{89} \mathrm{Zr}-$ CTB006 via the tail vein and PET/CT was performed at 168 hours after injection. The images showed that uptake of the tracer in CS225 tumors was significantly higher than that in CS263 tumors ( $p=0.037$ ) (figure 2). The RNAscope scores of CS225 and CS263 tumors were 4 and 3, respectively, which was consistent with the uptake of ${ }^{89} \mathrm{Zr}$-CTB006. There was no significant difference in the biodistribution in normal organs between the two groups.

\section{Patient characteristics in the clinical study}

In the clinical study, 21 patients (14 males, 7 females), including 12 patients with colorectal cancers and 9 patients with gastric cancers with a mean age of 58 years (range, 35-75), were enrolled from April 2019 to October 2019 (table 1). One patient withdrew for personal reasons after the first ${ }^{89} \mathrm{Zr}-\mathrm{CTB} 006 \mathrm{PET} / \mathrm{CT}$ scan.
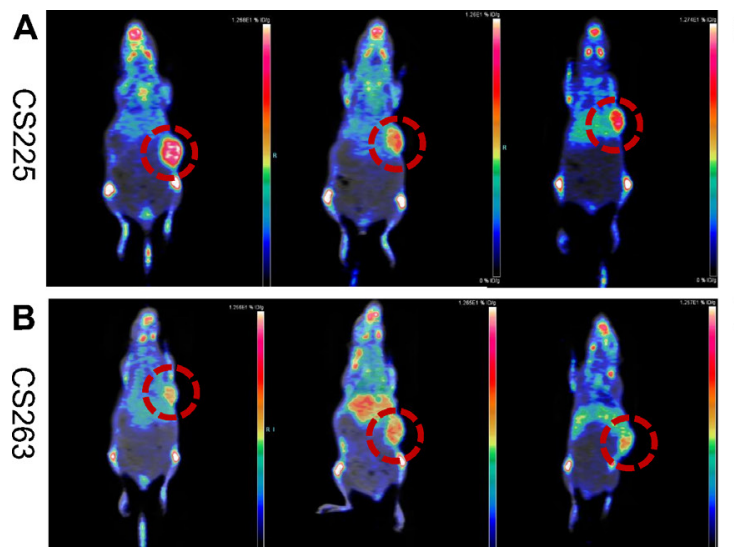
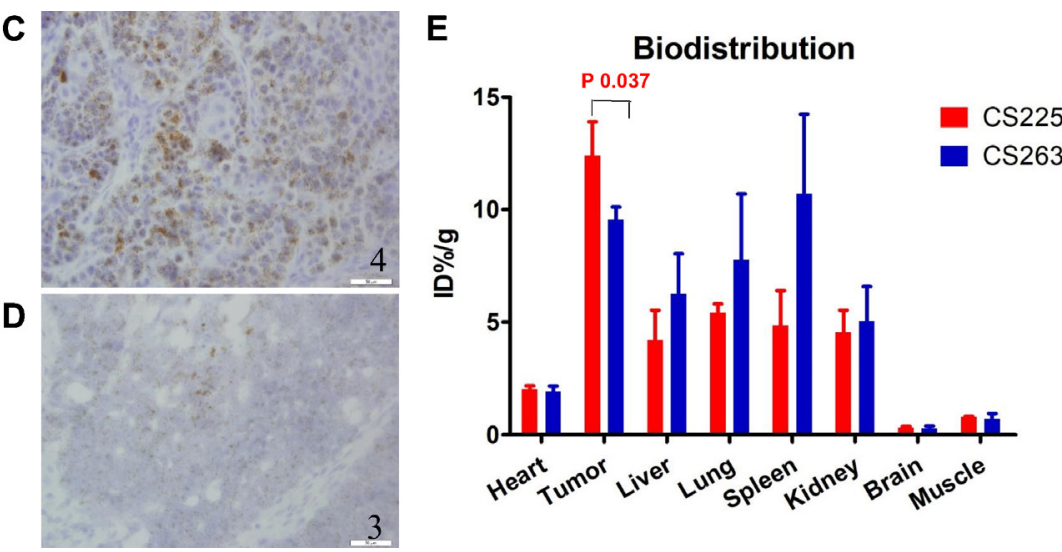

Figure $2{ }^{89} \mathrm{Zr}$-CTB006 Micro-PET/CT showed the uptake of ${ }^{89} \mathrm{Zr}$-CTB006 in CS225 tumors were significantly higher than CS263 tumors ( $p=0.037)$. (A, B) Micro-PET/CT of three high DR5 expression tumor model mice CS225 and three low DR5 expression tumor model mice CS263 demonstrated the uptake in tumors. (C, D) RNAscope score of CS225 and CS263 tumors were 4 and 3, respectively. (E) Biodistribution of ${ }^{89} \mathrm{Zr}$-CTB006 in the two groups showed there was no significant difference in normal organs of the two group mice. DR5, death receptor 5. 
Table 1 Patient characteristics

\begin{tabular}{ll} 
Characteristic & All patients (N=21) \\
\hline Age, years & \\
Mean & 58 \\
Range & $35-75$ \\
Sex, no of patients (\%) & \\
Male & $14(66.7 \%)$ \\
Female & $7(33.3 \%)$ \\
ECGO performance status & \\
0 & 21 \\
1 & 0 \\
Prior chemotherapy/radiotherapy & \\
Yes & 3 \\
No & 18 \\
Primary site of disease & \\
Stomach & 9 \\
Colon and rectum & 12
\end{tabular}

Histologic type of primary tumor

Adenocarcinoma 18

Adenocarcinoma with signet ring cell 3 carcinoma

\begin{tabular}{|ll}
\hline Histologic grade/differentiation & \\
\hline Advanced-moderately differentiated & 1 \\
\hline Moderately differentiated & 14 \\
\hline Moderately poorly differentiated & 1 \\
Poorly differentiated & 5 \\
Stage & \\
\hline I & 2 \\
II & 6 \\
\hline III & 8 \\
\hline IV & 5 \\
RNAscope score & \\
\hline 0 & 10 \\
\hline 1 & 3 \\
\hline 2 & 2 \\
\hline 3 & 2 \\
\hline 4 & 1 \\
\hline
\end{tabular}

ECOG, Eastern Cooperative Oncology Group.

\section{General pathology and RNAscope results in the operation cohort}

The pathology results obtained through surgical operation or endoscopy showed that there were 18 adenocarcinomas and 3 adenocarcinomas with signet ring cell carcinoma. The tumor tissues of 18 patients who underwent surgical operation were obtained and DR5 expression levels were detected by RNAscope. The RNAscope scores of ten patients were 0 ; those of three patients' were
1, two patients' scores were 2; two patients' scores were 3 , and one patient's score was 4 .

\section{Biodistribution of ${ }^{89} \mathrm{Zr}$-СTB006 from the first-in-human study}

A similar biodistribution pattern of ${ }^{89} \mathrm{Zr}$-CTB006 was observed in all patients and was in line with the metabolism of ${ }^{89} \mathrm{Zr}$ labeled antibodies in vivo. The $\mathrm{SUV}_{\text {mean }}$ of the main organs of the first 6 patients was measured to investigate the biodistribution in humans (figure 3 ). At 2 hours, most of the activity on the PET images was concentrated in the heart and major arteries. The liver and spleen also showed high uptake but lower uptake than the blood. At 24 hours, the tracer in the blood began to clear and the signal was reduced, as was the case in the spleen and liver. At 48 hours and 72 hours, the tracer continued clearing from the blood, and the signals in the blood, liver and spleen were decreased. The kidney, brain, lung, muscle showed low uptake. Some patients experienced earlier high uptake in the intestine at 48 hours and 72 hours, which influenced the imaging of intestinal tumors. Strikingly, throughout the whole examination from 2 to 120 hours, the adrenal glands sustained high accumulation and remained more stable than other organs such as the liver and spleen.

\section{Uptake of ${ }^{89} \mathrm{Zr}$-СТВ006 in tumors}

Except for the tumors in two patients, one with diffusetype, poorly differentiated adenocarcinoma with signet ring cell carcinoma and one with early gastric cancer, which showed no obvious uptake of ${ }^{18}$ F-FDG, the other 18 patients showed different levels of uptake in tumors on ${ }^{18}$ F-FDG PET/CT. The two ${ }^{18}$ F-FDG negative patients also showed no uptake of ${ }^{89} \mathrm{Zr}$-CTB006. The other patients showed different levels of uptake of ${ }^{89} \mathrm{Zr}$-CTB006 with a mean $\mathrm{SUV}_{\text {max }}$ of $6.63 \pm 3.29$ (range, 1.8-13.8) and the heterogeneity of uptake in tumors was more obvious than that of ${ }^{18}$ F-FDG. At 24 hours, the tumor was distinguishable but had low contrast to the background. The uptake of tumors peaked at 48 hours in most patients and was still visible at 120 hours. Optimal tumor visualization was generally obtained at 72 hours after injection with the highest tumor background ratio. The highest $\mathrm{SUV}_{\max }$ of 13.8 in the tumor was observed in a patient with colon cancer (No.7). Uptake in colorectal cancers was significantly higher than that in gastric cancers (SUV $_{\text {max }} 48$ hours: $7.61 \pm 3.19$ vs $3.96 \pm 1.56, \mathrm{p}=0.008$; $\mathrm{SUV}_{\max }$ 72 hours: $7.61 \pm 3.04$ vs $3.96 \pm 1.82, \mathrm{p}=0.007$ ) (figure $4 \mathrm{C}, \mathrm{D}$ ). There was a significant positive correlation between the $\mathrm{SUV}_{\max }$ of tumors on ${ }^{89} \mathrm{Zr}$-CTB006 PET/CT at 72 hours and that on ${ }^{18}$ F-FDG PET/CT (R: 0.785, p<0.001) (online supplemental figure $2 \mathrm{~B}$ ).

Uptake of ${ }^{89} \mathrm{Zr}$-CTB006 was also observed in most metastatic lesions but varied in different sites. The liver metastasis had the highest uptake in a female patient in her early 60s with sigmoid colon cancer (no.7), showing uneven uptake of ${ }^{89} \mathrm{Zr}$-CTB006 with an $\mathrm{SUV}_{\text {max }}$ of 8.8 (72 hours) (figure $5 \mathrm{~B}-\mathrm{D})$. A gastric cancer female patient in her early 40s (no. 16) with perineal and bone metastasis 


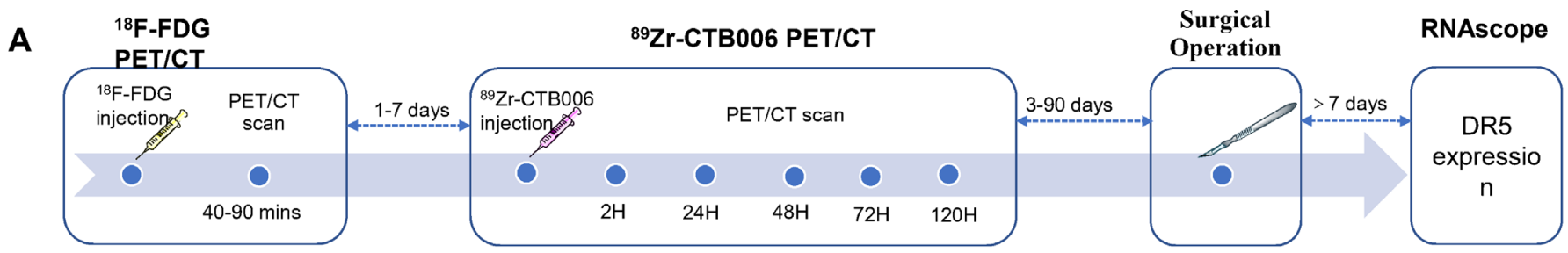

B

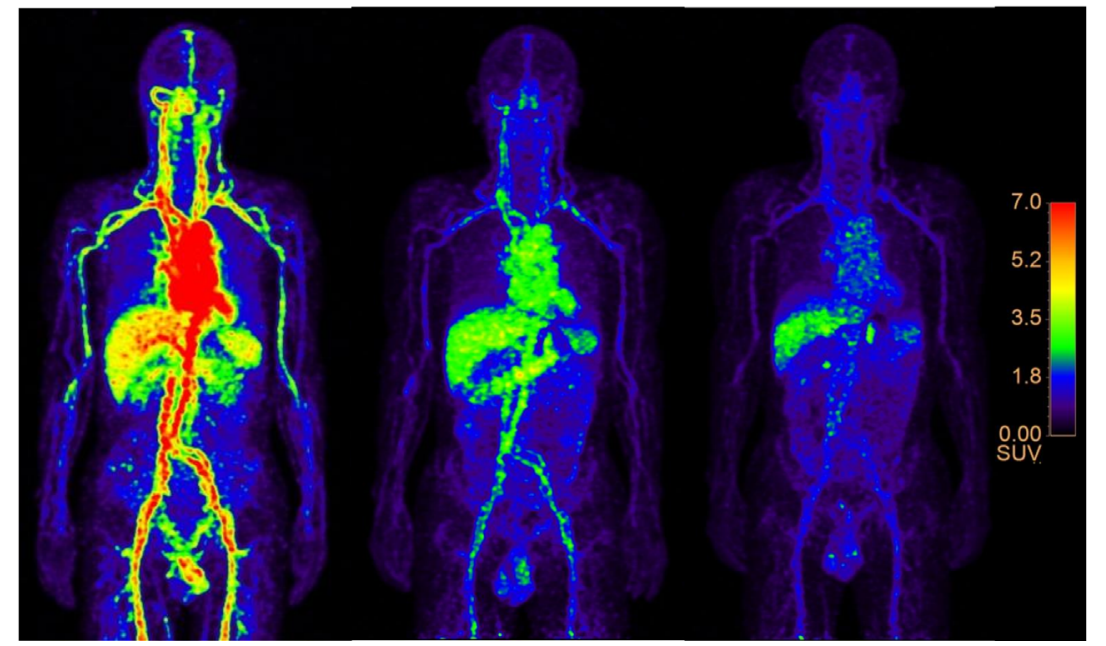

C

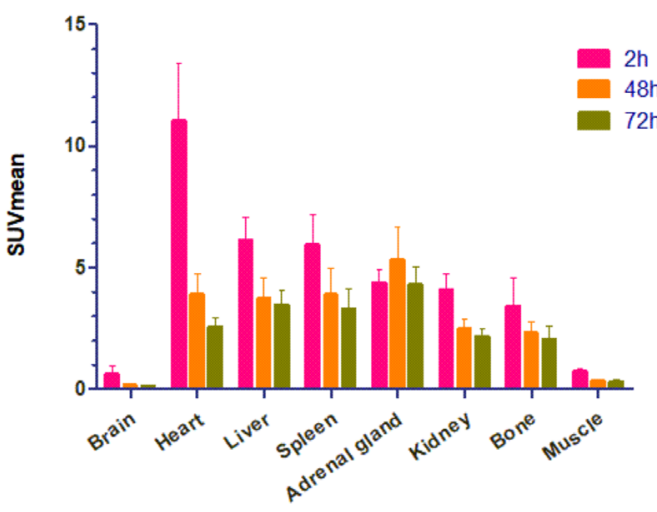

Figure 3 Study design, PET/CT-images of patient 5, biodistribution in patients. (A) Study design. (B) The maximum-intensityprojection reconstruction images of ${ }^{89} \mathrm{Zr}$-CTB006 PET/CT in patient five demonstrated: (1) heart and major arteries showed high uptake of tracer at first, but the signal reduced with time; (3) the adrenal glands sustained high accumulation and maintained stable during the whole examination; (3) background such as brain showed low uptake. (C) Biodistribution in patients showed high uptake heart, liver and spleen. DR5, death receptor 5; SUV ${ }_{\max }$, maximum standardized uptake value.

showed high uptake in the metastatic lesions, and the bone metastasis showed higher uptake on ${ }^{89} \mathrm{Zr}$-CTB006 PET/CT than on ${ }^{18}$ F-FDG PET/CT (online supplemental figure 3). The uptake of ${ }^{89} \mathrm{Zr}$-CTB006 at 48 hours in the metastatic lesions was significantly lower than that in the primary lesions in the operation cohort $\left(\mathrm{SUV}_{\max }\right.$ : $6.97 \pm 3.14$ vs $4.22 \pm 2.45, \mathrm{p}=0.0135$ ), but not at 72 hours $\left(\mathrm{SUV}_{\max }\right.$ : 5.18 \pm 2.63 vs $\left.3.52 \pm 2.19, \mathrm{p}=0.0704\right) \quad$ (online supplemental figure $4 \mathrm{~A}, \mathrm{~B}$ ).

The uptake of ${ }^{89} \mathrm{Zr}$-CTB006 in tumors at 48 hours was significantly higher in gastric cancer patients with stage III-IV disease than in those with stage I-II disease(SU$\mathrm{V}_{\max }: 4.82 \pm 1.63$ vs $\left.2.2, \mathrm{p}<0.0001\right)$. Nevertheless, uptake in colorectal cancer patients with stage III-IV disease was significantly lower than that in patients with stage I-II disease $\left(\mathrm{SUV}_{\text {max }}: 6.09 \pm 2.25\right.$ vs $\left.10.48 \pm 2.96, \mathrm{p}=0.015\right)$ (online supplemental figure 4C). No difference in uptake of ${ }^{89} \mathrm{Zr}$-CTB006 was observed between different degrees of differentiation or different pathological types of gastric cancers or colorectal cancers.

The $\mathrm{SUV}_{\max }$ of the primary tumors in patients with colorectal cancers who had received radiotherapy or chemotherapy was significantly lower than that in patients without treatment on the 48 hours ${ }^{89} \mathrm{Zr}$-CTB006 PET/CT $\left(\mathrm{SUV}_{\max }: 4.83 \pm 0.51\right.$ vs $8.94 \pm 3.28, \mathrm{p}=0.005$ ) (online supplemental figure $2 \mathrm{C}$ ).

\section{Correlations with ${ }^{89} \mathrm{Zr}$-CTB006 uptake and RNAscope score}

The tumor uptake of ${ }^{89} \mathrm{Zr}$-CTB006 in patients with RNAscope scores of 3-4 was significantly higher than that in patients with scores of $0-2$ (SUV $_{\max } 48$ hours: $12.50 \pm 1.47$ vs $5.49 \pm 2.26, \mathrm{p}<0.001$; 72 hours: $9.30 \pm 2.00$ vs $4.41 \pm 2.00, \mathrm{p}=0.001$ ) (figures $4 \mathrm{~A}, \mathrm{~B}$ and 6 ). The tumor uptake of ${ }^{18} \mathrm{~F}$-FDG was also significantly higher in patients with RNAscope scores of 3-4 than in those with scores of $0-2\left(\mathrm{SUV}_{\max }: 17.55 \pm 3.90\right.$ vs $\left.9.60 \pm 6.05, \mathrm{p}=0.046\right)$ (online supplemental figure 2D).

The adrenal glands of all patients showed stable uptake during the whole examination, and patients with higher tumor uptake than adrenal glands were more likely to have DR5 overexpression (figure 4E). ROC curves were obtained by comparing DR5 expression status with $\mathrm{SUV}_{\text {max }}$ at 48 hours, 72 hours and $\mathrm{SUV}_{\text {ratio }}$ (ratio of $\mathrm{SUV}_{\text {max }}$ of tumor vs $\mathrm{SUV}_{\text {mean }}$ of the adrenal glands) at 48 hours on ${ }^{89} \mathrm{Zr}$-CTB006 PET/CT (figure 4F). The areas under the curve were $0.976,0.905$ and 0.9091 , respectively, with $\mathrm{p}<0.05$ (figure $4 \mathrm{~F}$ ). An SUVmax of 9.3 at 48 hours and 6.3 at 72 hours could be used to discriminate DR5 expression status of tumors both with a sensitivity and specificity of $100 \%$ and $92.9 \%$, respectively. When a ratio of 1.38 was used to discriminate the DR5 expression status of tumors, the sensitivity and specificity of the model were $100 \%$ and $78.6 \%$, respectively. 
A

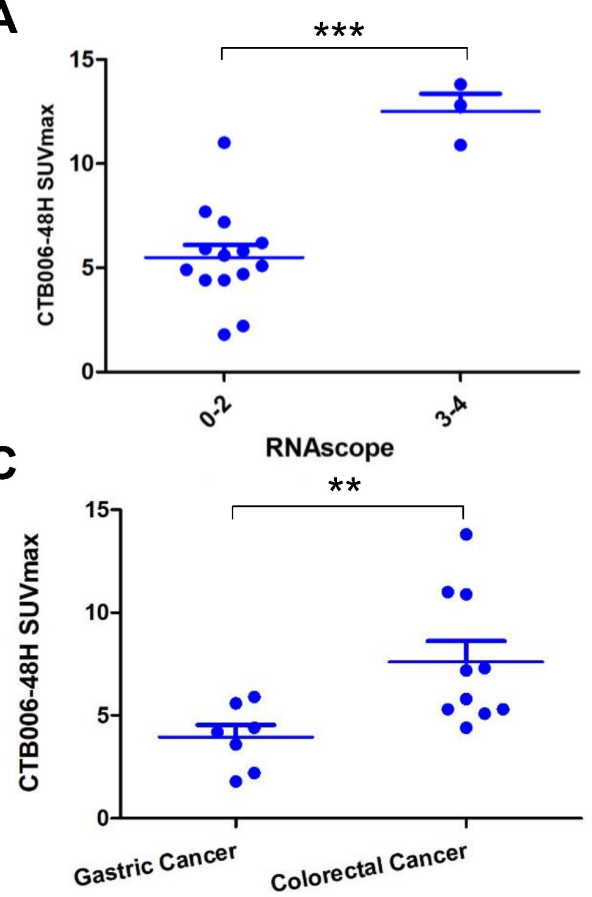

$\mathbf{E}$

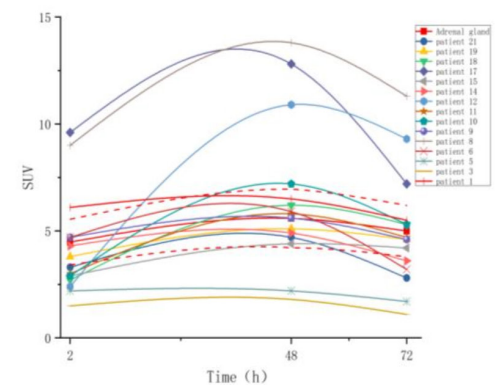

B

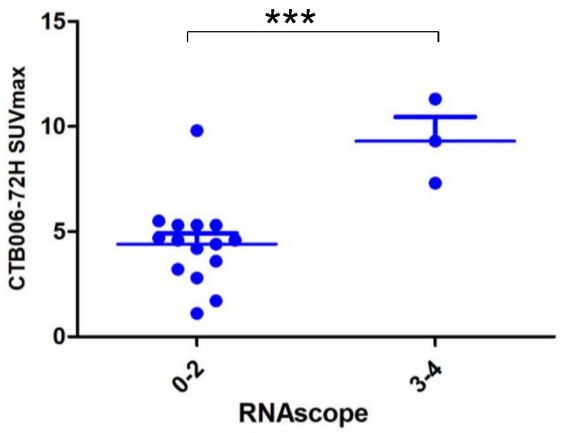

D

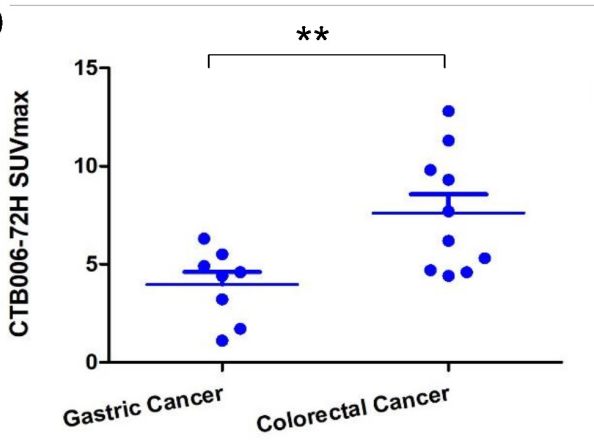

$\mathbf{F}$

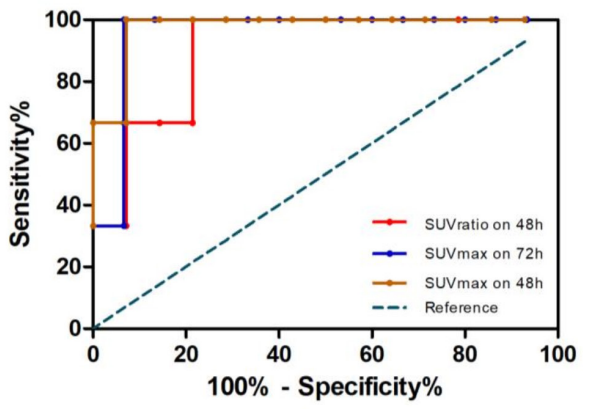

Figure 4 Tracer uptake in different DR5 expression status by RNAscope and tumor types. (A, B) The tumor uptake of ${ }^{89} \mathrm{Zr}$-CTB006 in patients with RNAscope score 3-4 was significantly higher than that in patients with score 0-2 (mean SUV $_{\max } 48$ hours: $12.50 \pm 1.47$ vs $5.49 \pm 2.26, p<0.001$; 72 hours: $9.30 \pm 2.00$ vs $4.41 \pm 2.00, p=0.001$ ). (C, D) The uptake of ${ }^{89} \mathrm{Zr}$ CTB006 in colorectal cancer was significantly higher than that in gastric cancer (48hours: $7.61 \pm 3.19$ vs $3.96 \pm 1.56, p=0.008$; 72 hours:7.61 \pm 3.04 vs $3.96 \pm 1.82, p=0.007$ ). (E) Tumors with higher uptake than adrenal gland had higher DR5 expression (the dotted line represented the SD of adrenal glands uptake in all patients). (F) Receiver operating characteristic curve representing the sensitivity and specificity of SUV max $_{0}$ on 48 hours, 72 hours and SUV ratio $_{\text {(ratio of SUV }}$ max of tumor vs SUV mean $_{\text {of the adrenal }}$ glands) on 48 hours ${ }^{89} \mathrm{Zr}$-CTB006 PET/CT with the area under the curve of $0.976,0.905^{\max }$ and $0.9091(P<0.05)$ respectively. DR5, death receptor 5 ; SUV ${ }_{\max }$, maximum standardized uptake value. ${ }^{* \star *}: \mathrm{p} \leq 0.001 ;{ }^{* *}: \mathrm{p} \leq 0.01$.

\section{Safety evaluation and dosimetry of ${ }^{89} \mathrm{Zr}$-СTB006 in patients}

There were no related adverse events or clinically detectable pharmacological effects in any of the patients. No significant changes were observed in vital signs, or laboratory tests or ECG. The dosimetry estimated from OLINDA showed that the organs receiving the highest absorbed doses were the liver and spleen with mean values of 1.42 and $1.17 \mathrm{mGy} / \mathrm{MBq}$, respectively (online supplemental table 3). The mean effective dose was $0.349 \mathrm{mSv} / \mathrm{MBq}$ (1.29 rem/mCi).

\section{DISCUSSION}

At present, chemotherapy usually leads to many strong side effects due to its non-selective cytotoxic effect. Therefore, there is an urgent need to investigate an antitumor drug that could selectively kill tumor cells with fewer side effects. Since being reported in 1995, TRAIL has shown selective apoptosis induction in vivo and has received widespread attention. ${ }^{15-18}$ Many humanized DR5 agonistic antibodies showed stable tumor cell selective apoptosis-inducing capabilities in preclinical research and were successively introduced into clinical trials. ${ }^{19}$ Although phase I clinical trials showed good safety and good antitumor effects in some patients, phase II clinical trials combined with chemotherapy failed to improve the antitumor efficacy of the combined chemotherapy drugs. ${ }^{20}$

Therefore, it is necessary to develop a method to identify patients who would benefit from DR5 agonist antibody therapy, which will make it easier to achieve 
A

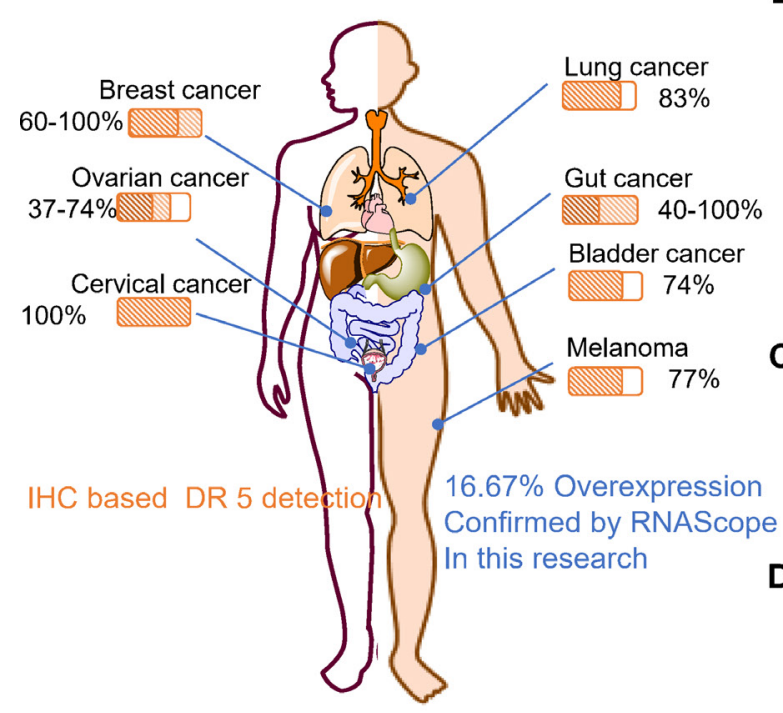

B

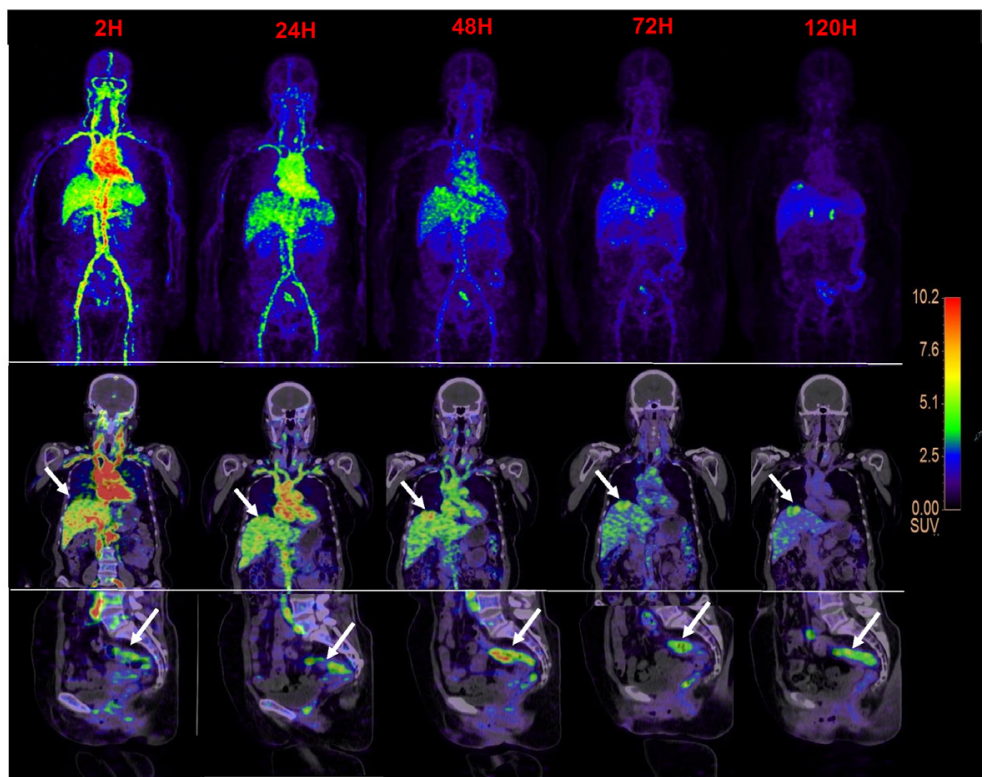

Figure 5 (A) DR5 expression rates in some common cancers in previous literatures. (B-D) MIP reconstruction images (B), the coronal (C) and sagittal (D) PET-CT fused images on 2 hours, 24 hours, 48 hours, 72 hours, and 120 hours in patient seven showed both of the primary tumor lesion and the liver metastatic lesion (arrow) showed high uptake of tracer. DR5, death receptor 5; IHC, immunohistochemistry; MIP, maximum intensity projection.

success inclinical trials. Previously, it was reported that ${ }^{111}$ In-CS1008 SPECT could reveal the interpatient and intrapatient heterogeneity of DR5 expression in patients with metastatic colorectal cancer and was predictive of DR5 agonist efficacy. ${ }^{13}$ However, ${ }^{111}$ In-CS1008 uptake in tumors did not correlate with DR5 expression detected by immunohistochemistry (IHC) in the achieved tumor samples. This finding might be because SPECT cannot quantitatively analyze radioactive uptake with low spatial resolution, suggesting that it was premature to use ${ }^{111} \mathrm{In}$ CS1008 SPECT clinically. PET can not only use the SUV value to qualitatively analyze uptake, but also has a higher spatial resolution and higher sensitivity, indicating that PET is a better approach than SPECT. Another reason might be the lack of DR5 antibodies reactive on paraffin sections, which has limited the application of IHC. To date, there has been no systematic survey of the sensitivity and specificity of currently used antibodies in detecting DR5 expression. RNAscope is a novel RNA ISH method that allows for the visualization of specific gene expression in tumor cells and is known for its higher sensitivity and specificity than traditional IHC methods. ${ }^{21}$ When IHC is not available or is difficult to standardize, RNAscope is a promising and sensitive method for the detection of target RNA in cells. RNAscope technology can provide an effective supplement for IHC detection when there is no effective antibody or the antibody sensitivity/specificity cannot meet the clinical needs, and has a more sensitive detection rate than IHC. ${ }^{22}$ mRNA detected by RNAscope demonstrated a positive association with protein status as determined by IHC. $^{22}$

Herein, we first reported that ${ }^{89} \mathrm{Zr}-\mathrm{CTB} 006 \mathrm{PET} / \mathrm{CT}$ imaging was safe in humans and could detect primary and metastatic lesions and DR5 expression levels effectively in gastrointestinal cancers. The biodistribution of ${ }^{89} \mathrm{Zr}$ CTB006 in humans was in line with the metabolism of ${ }^{89} \mathrm{Zr}$-labeled antibodies in vivo, which was consistent with the PET/CT imaging results of previously reported ${ }^{89} \mathrm{Zr}$-labeled antibodies. ${ }^{23} 24$ The probe was mainly concentrated in the heart and blood vessels, liver and spleen after administration. Clearance from the blood, liver, spleen began at 24 hours and the tumor visualization became obvious. At 72 hours, the contrast between the tumor and the background was optimal. Astonishingly, the adrenal glands maintained stable high uptake during the whole imaging process, and that the uptake decreased more slowly with time than other organs, which has not been reported previously. The attempts have been made to verify DR5 expression levels in the tissue samples of human adrenal gland by RNAscope and western blot analysis. However, both assays did not yield positive results. We believe both quality of tissue samples and detection sensitivity might be the issues. Thus far, the toxicity against adrenal glands by DR5 antibody has not been reported in clinical trials. Hence, whether this finding is because of DR5 overexpression in the adrenal glands or other reasons still needs further research. Compared with the four tracers previously reported by Bensch et $a l^{25}{ }^{89} \mathrm{Zr-CTB} 006$ showed a comparable distribution pattern in the whole body. Healthy liver tissue as well as in the spleen, kidneys and intestines showed higher tracer concentrations. The bone marrow, lung and brain showed lower tracer concentrations. However, the higher concentration in the adrenal glands was different from the four tracers. However, due to the small volume, the adrenal glands only contained approximately $0.04 \%$ ID.

In the current study, over $50.0 \%(10 / 18)$ of patients had no DR5 expression, and only $16.7 \%$ (3/18) of 
${ }^{18}$ F-FDG

A

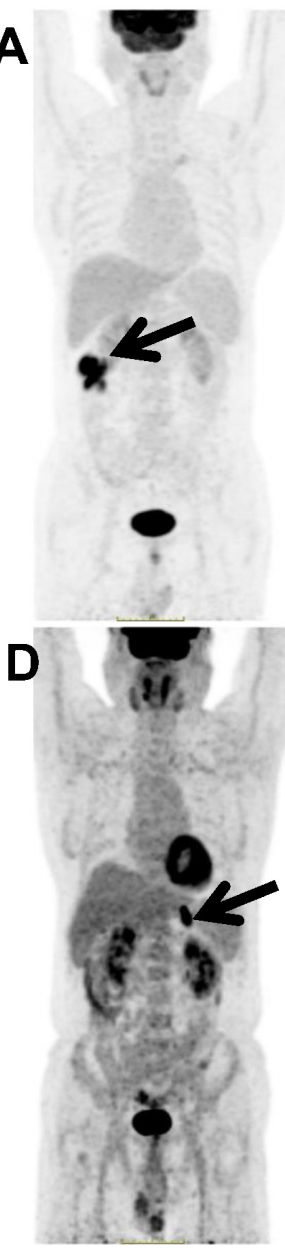

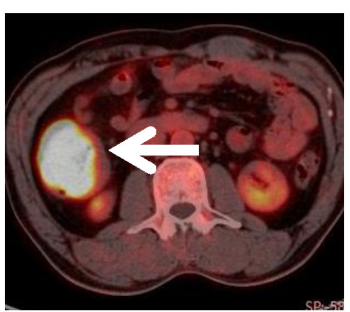
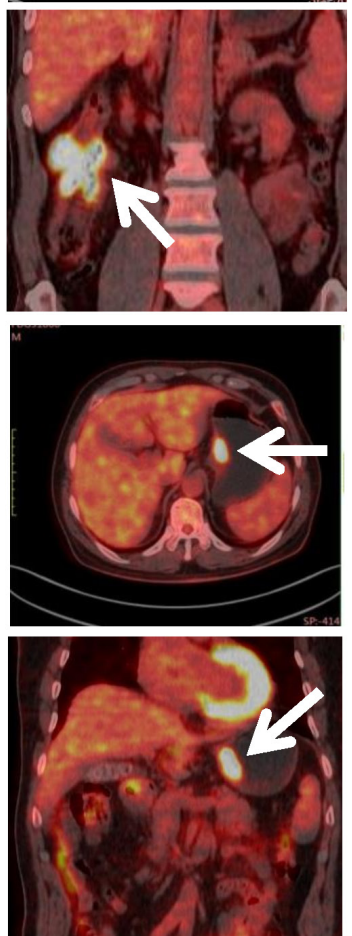

${ }^{89} \mathrm{Zr}-\mathrm{CTB} 006$

B

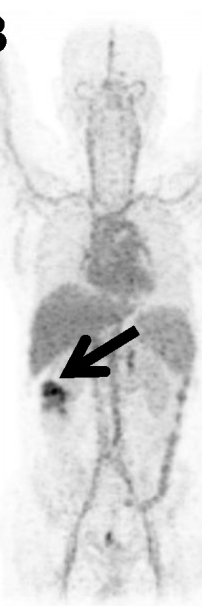

E

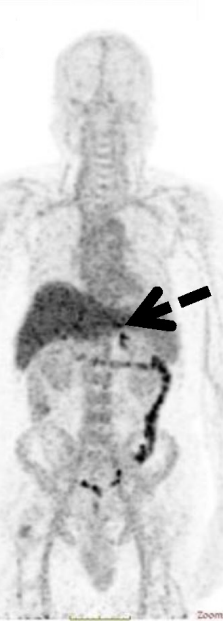

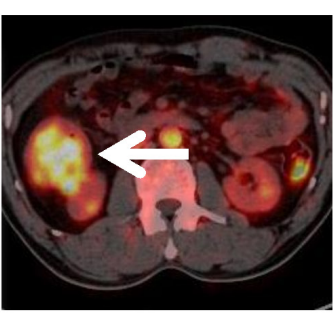
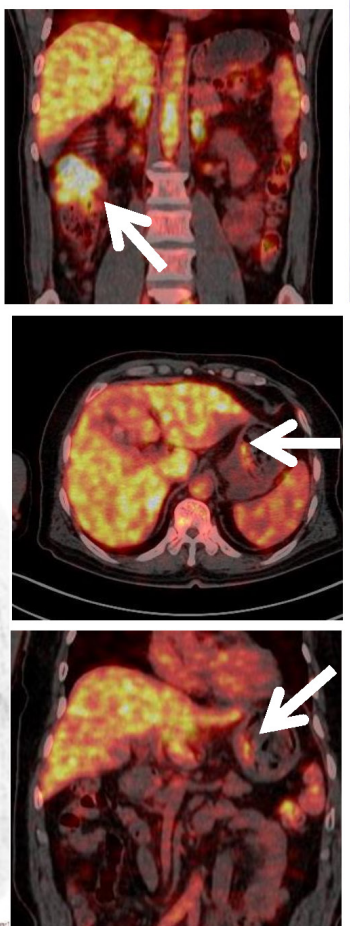

RNAscope
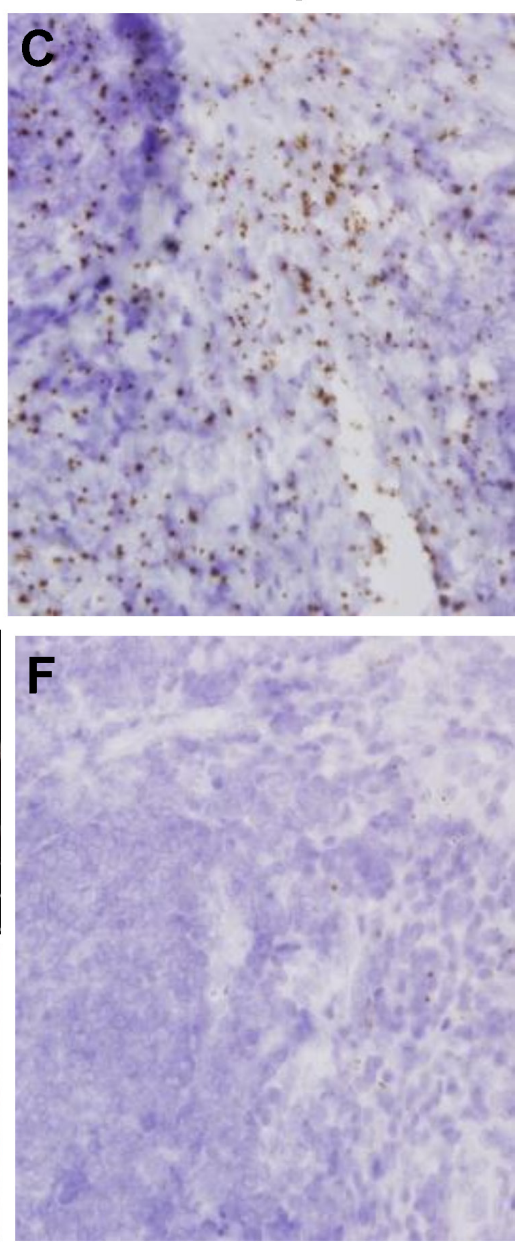

Figure 6 PET/CT images and RNAscope staining of patient 17 and 1. (A) MIP image, the axial and coronal PET-CT fused images of ${ }^{18} \mathrm{~F}$-FDG PET/CT of patient 17 showed high uptake of ${ }^{18} \mathrm{~F}-\mathrm{FDG}$ in tumor (arrow). (B) MIP image, the axial and coronal PET-CT fused images of ${ }^{89} \mathrm{Zr}$-CTB006 PET/CT of patient 17 showed high uptake of ${ }^{89} \mathrm{Zr}$-CTB006 in tumor (arrow). (C) RNAscope score of the patient 17 was 3 (40X). (D) MIP image, the axial and coronal PET-CT fused images of ${ }^{18} \mathrm{~F}-\mathrm{FDG}$ PET/CT of patient one showed high uptake of ${ }^{18} \mathrm{~F}-\mathrm{FDG}$ in tumor (arrow). (E) MIP image, the axial and coronal PET-CT fused images of ${ }^{89} \mathrm{Zr}$-CTB006 PET/CT of patient one showed low uptake of ${ }^{89} \mathrm{Zr}$-CTB006 in tumor (arrow; the DASH arrow indicates the unclearly tumor lesion). (F) RNAscope score of patient 1 was 0 (40X). MIP, maximum intensity projection.

patients had DR5 overexpression in tumors, which indicated that the rate of DR5 expression was not as high as previously reported. ${ }^{26}$ This finding may also be the reason why only a subset of patients in the previous clinical trials showed antitumor effects, and no trials could achieve the endpoint of improving the efficacy in unselected patients. ${ }^{27}$ It might be because of the inaccurate detection of DR5 by IHC in previous studies, resulting in the overestimation of the DR5 expression rate in tumors. Although ${ }^{111}$ In-CS1008 SPECT has been reported to be able to predict DR5 expression in patients' tumors, it has not been used clinically due to its low resolution and inability to quantify.

In this study, we demonstrated that ${ }^{89} \mathrm{Zr}-\mathrm{CTB} 006 \mathrm{PET} /$ CT could clearly detect primary and metastatic tumor lesions and could quantitatively measure uptake in tumors to distinguish the DR5 expression status from animals to patients. The uptake of ${ }^{89} \mathrm{Zr}$-CTB006 in tumors with RNAscope scores of 3-4 was significantly higher than that of tumors with scores of $0-2$. An SUV max $_{\text {of }} 9.3$ at 48 hours and 6.3 at 72 hours could be used to discriminate the DR5 expression status of tumors both with a sensitivity and specificity of $100 \%$ and $92.9 \%$, respectively. Tumors with higher ${ }^{89} \mathrm{Zr}$-СТВ006 uptake than adrenal glands were more likely to overexpress DR5, indicating that the uptake of adrenal glands could be a cut-off value to identify tumors with DR5 overexpression. The tumor-to-adrenal uptake ratio of 1.38 at 48 hours was an effective cut-off value to discriminate the DR5 expression status of tumors with a sensitivity and specificity of $100 \%$ and $78.6 \%$, respectively. Furthermore, animal experiments in PDX mice demonstrated that ${ }^{89} \mathrm{Zr}$-CTB006 PET/CT could determine DR5 expression in tumors with RNAscope scores of 3 and 4, which needs to be validated by a clinical trial with a large sample size. It is suggested that ${ }^{89} \mathrm{Zr}$-CTB006 PET/CT can be used for the noninvasive detection of DR5 expression levels and has the potential to identify patients benefiting from DR5 agonist antibody treatment. 
${ }^{89} \mathrm{Zr}$-CTB006 uptake in patients who had received radiotherapy or chemotherapy was significantly lower than that in patients without treatment. This finding might indicate that radiotherapy and chemotherapy could downregulate DR5 expression levels and might also be a reason why DR5 agonists could not improve the antitumor activity of chemotherapy in clinical trials, ${ }^{28} 29$ although preclinical evidence of antitumor effects has been described in combination with chemotherapy. ${ }^{30}{ }^{31}$ A previous study reported that DR5 expression in liver tissue and that TRAIL could induce apoptosis in the human liver, while hepatocytes from rats, mice and rhesus monkeys were not sensitive to human TRAIL. The study indicated that there were considerable differences between species in their response to TRAIL. ${ }^{32}$ The preclinical investigation results in other species should be taken with caution and preclinical evaluation of DR5 targeted antitumor treatment should include investigation with human cells.

\section{CONCLUSION}

Taken together, the study developed a noninvasive approach ${ }^{89} \mathrm{Zr}$-CTB006 PET/CT to detect DR5 overexpressing tumors based on molecular imaging and suggested that ${ }^{89} \mathrm{Zr}-\mathrm{CTB} 006 \mathrm{PET} / \mathrm{CT}$ has the potential to identify DR5 overexpressing patients. This study is the first to find high uptake in adrenal glands that could be an internal marker to distinguish DR5 overexpression, but the reason still needs further research. We also found that the rate of DR5 overexpression in tumor patients was substantially lower than that reported previously, which might explain the failure of clinical trials and needs further investigation.

\section{Author affiliations}

${ }^{1}$ Department of Nuclear Medicine, Peking University Cancer Hospital \& Institute, Beijing, China

${ }^{2}$ NMPA Key Laboratory for Research and Evaluation of Radiopharmaceuticals (National Medical Products Administration), Beijing, China

${ }^{3}$ Key Laboratory of Carcinogenesis and Translational Research (Ministry of Education/Beijing), Beijing, China

${ }^{4}$ Department of Gastrointestinal Surgery, Peking University Cancer Hospital \& Institute, Beijing, China

${ }^{5}$ Department of Cell Biology and Divisions of Clinical Immunology and

Rheumatology, University of Alabama at Birmingham, Birmingham, Alabama, USA

Contributors Conception and design: SW, HZ, YL, TZ, NL, AW and ZY. Financial support: HZ, NL and ZY. Administrative support: NL, AW and ZY. Collection and assembly of data: SW, HZ, YL, JD, FW, LD, XW, JZ, YZ, YY, NL, AW and ZY. Data analysis and interpretation: SW, HZ, YL, TZ, NL, AW and ZY. Manuscript writing: all authors. Final approval of manuscript: all authors. Accountable for all aspects of the work: all authors.

Funding This work was supported by the National Science and Technology Major Project (No. 2020ZX09201023), National Natural Science Foundation of China (81671733, 81871386, and 81871387), Beijing Municipal Administration of Hospitals-Yangfan Project (ZYLX201816), Beijing Hospitals Authority' Ascent Plan (DFL20191102), Beijing Excellent Talents Funding (2017000021223ZK33), Beijing Millions of Talent Projects A level funding (No. 2019A38), Beijing Hospitals Authority Clinical Medicine Development of Special Funding Support (ZYLX202116).

Competing interests No, there are no competing interests.

Patient consent for publication Not required.
Ethics approval The clinical trial approved by the Ethics Committee of Beijing Cancer Hospital (Ethical No. 2018YJZ64).

Provenance and peer review Not commissioned; externally peer reviewed.

Data availability statement Data are available on reasonable request. The datasets generated during and/or analyzed during the current study are available from the corresponding author on reasonable request.

Supplemental material This content has been supplied by the author(s). It has not been vetted by BMJ Publishing Group Limited (BMJ) and may not have been peer-reviewed. Any opinions or recommendations discussed are solely those of the author(s) and are not endorsed by BMJ. BMJ disclaims all liability and responsibility arising from any reliance placed on the content. Where the content includes any translated material, BMJ does not warrant the accuracy and reliability of the translations (including but not limited to local regulations, clinical guidelines, terminology, drug names and drug dosages), and is not responsible for any error and/or omissions arising from translation and adaptation or otherwise.

Open access This is an open access article distributed in accordance with the Creative Commons Attribution Non Commercial (CC BY-NC 4.0) license, which permits others to distribute, remix, adapt, build upon this work non-commercially, and license their derivative works on different terms, provided the original work is properly cited, appropriate credit is given, any changes made indicated, and the use is non-commercial. See http://creativecommons.org/licenses/by-nc/4.0/.

\section{ORCID iD}

Zhi Yang http://orcid.org/0000-0003-2084-5193

\section{REFERENCES}

1 Fancy RM, Kim H, Zhou T, et al. Calmodulin binding to death receptor 5-mediated death-inducing signaling complex in breast cancer cells. J Cell Biochem 2017;118:2285-94.

2 Rowinsky EK. Targeted induction of apoptosis in cancer management: the emerging role of tumor necrosis factor-related apoptosis-inducing ligand receptor activating agents. J Clin Oncol 2005;23:9394-407.

3 Takeda K, Stagg J, Yagita H, et al. Targeting death-inducing receptors in cancer therapy. Oncogene 2007;26:3745-57.

4 Zhou T, Mountz JD, Kimberly RP. Immunobiology of tumor necrosis factor receptor superfamily. Immunol Res 2002;26:323-36.

5 Graves JD, Kordich JJ, Huang T-H, et al. Apo2L/Trail and the death receptor 5 agonist antibody AMG 655 cooperate to promote receptor clustering and antitumor activity. Cancer Cell 2014;26:177-89.

6 Subbiah V, Brown RE, Buryanek J, et al. Targeting the apoptotic pathway in chondrosarcoma using recombinant human Apo2L/TRAIL (dulanermin), a dual proapoptotic receptor (DR4/DR5) agonist. Mol Cancer Ther 2012;11:2541-6.

7 Riccioni R, Pasquini L, Mariani G, et al. Trail decoy receptors mediate resistance of acute myeloid leukemia cells to TRAIL. Haematologica 2005;90:612-24.

8 Daniels RA, Turley H, Kimberley FC, et al. Expression of TRAIL and TRAIL receptors in normal and malignant tissues. Cell Res 2005;15:430-8.

9 Buchsbaum DJ, Zhou T, Lobuglio AF. Trail receptor-targeted therapy. Future Oncol 2006;2:493-508.

10 Kretz A-L, Trauzold A, Hillenbrand A, et al. TRAILblazing strategies for cancer treatment. Cancers 2019;11:456.

11 Paz-Ares L, Bálint B, de Boer $\mathrm{RH}$, de $\mathrm{BRH}$, et al. A randomized phase 2 study of paclitaxel and carboplatin with or without conatumumab for first-line treatment of advanced non-small-cell lung cancer. $J$ Thorac Oncol 2013;8:329-37.

12 Fuchs CS, Fakih M, Schwartzberg L, et al. Trail receptor agonist conatumumab with modified FOLFOX6 plus bevacizumab for firstline treatment of metastatic colorectal cancer: a randomized phase 1b/2 trial. Cancer 2013;119:4290-8.

13 Ciprotti M, Tebbutt NC, Lee F-T, et al. Phase I imaging and pharmacodynamic trial of CS-1008 in patients with metastatic colorectal cancer. J Clin Oncol 2015;33:2609-16.

14 Wang F, Flanagan J, Su N, et al. RNAscope: a novel in situ RNA analysis platform for formalin-fixed, paraffin-embedded tissues. $J$ Mol Diagn 2012;14:22-9.

15 Wiley SR, Schooley K, Smolak PJ, et al. Identification and characterization of a new member of the TNF family that induces apoptosis. Immunity 1995;3:673-82.

16 Pitti RM, Marsters SA, Ruppert S, et al. Induction of apoptosis by Apo-2 ligand, a new member of the tumor necrosis factor cytokine family. J Biol Chem 1996;271:12687-90. 
17 Walczak H, Miller RE, Ariail K, et al. Tumoricidal activity of tumor necrosis factor-related apoptosis-inducing ligand in vivo. Nat Med 1999;5:157-63.

18 Ashkenazi A, Pai RC, Fong S, et al. Safety and antitumor activity of recombinant soluble Apo2 ligand. J Clin Invest 1999;104:155-62.

19 Cheng A-L, Kang Y-K, He AR, et al. Safety and efficacy of tigatuzumab plus sorafenib as first-line therapy in subjects with advanced hepatocellular carcinoma: a phase 2 randomized study. $J$ Hepatol 2015;63:896-904.

20 Forero-Torres A, Varley KE, Abramson VG, et al. TBCRC 019: a phase II trial of nanoparticle albumin-bound paclitaxel with or without the Anti-Death receptor 5 monoclonal antibody Tigatuzumab in patients with triple-negative breast cancer. Clin Cancer Res 2015;21:2722-9.

21 Tamma R, Annese T, Ruggieri S, et al. Vegfa and VEGFR2 RNAscope determination in gastric cancer. J Mol Histol 2018;49:429-35.

22 Duncan DJ, Scott M, Scorer P, et al. Assessment of PD-L1 mRNA and protein expression in non-small cell lung cancer, head and neck squamous cell carcinoma and urothelial carcinoma tissue specimens using RNAScope and immunohistochemistry. PLoS One 2019;14:e0215393-6203.

23 Bensch F, van der Veen EL, Lub-de Hooge MN, Hooge MNL, et al. ${ }^{89} \mathrm{Zr}$-atezolizumab imaging as a non-invasive approach to assess clinical response to PD-L1 blockade in cancer. Nat Med 2018;24:1852-8.

24 Niemeijer AN, Leung D, Huisman MC, et al. Whole body PD-1 and PD-L1 positron emission tomography in patients with non-small-cell lung cancer. Nat Commun 2018;9:4664.

25 Bensch F, Smeenk MM, van Es SC, et al. Comparative biodistribution analysis across four different ${ }^{89} \mathrm{Zr}$-monoclonal antibody tracers-
The first step towards an imaging warehouse. Theranostics 2018;8:4295-304.

26 Dubuisson A, Favreau C, Fourmaux E, et al. Generation and characterization of novel anti-DR4 and anti-DR5 antibodies developed by genetic immunization. Cell Death Dis 2019;10:101.

27 Hong DS, Kurzrock R, Supko JG, et al. A phase I first-in-human trial of bardoxolone methyl in patients with advanced solid tumors and lymphomas. Clin Cancer Res 2012;18:3396-406.

28 Forero-Torres A, Infante JR, Waterhouse D, et al. Phase 2, multicenter, open-label study of tigatuzumab (CS-1008), a humanized monoclonal antibody targeting death receptor 5 , in combination with gemcitabine in chemotherapy-naive patients with unresectable or metastatic pancreatic cancer. Cancer Med 2013;2:925-32.

29 Reck M, Krzakowski M, Chmielowska E, et al. A randomized, double-blind, placebo-controlled phase 2 study of tigatuzumab (CS-1008) in combination with carboplatin/paclitaxel in patients with chemotherapy-naïve metastatic/unresectable non-small cell lung cancer. Lung Cancer 2013;82:441-8.

30 Arafat W, Zhou T, Naoum GE, et al. Targeted radiotherapy potentiates the cytotoxicity of a novel anti-human DR5 monoclonal antibody and the adenovirus encoding soluble TRAIL in prostate cancer. J Egypt Natl Canc Inst 2015;27:205-15.

31 Lei G, Xu M, Xu Z, et al. Combination of novel DR5 targeting agonistic scFv antibody TR2-3 with cisplatin shows enhanced synergistic antitumor activity in vitro and in vivo. Biomed Pharmacother 2018:98:271-9.

32 Jo M, Kim TH, Seol DW, et al. Apoptosis induced in normal human hepatocytes by tumor necrosis factor-related apoptosis-inducing ligand. Nat Med 2000;6:564-7. 